\title{
Formation Features of Hybrid Magnetic Materials Based on Polyphenoxazine and Magnetite Nanoparticles
}

\author{
S.Zh. Ozkan ${ }^{1, *}$, G.P. Karpacheva ${ }^{1}$, E.L. Dzidziguri ${ }^{2}$, P.A. Chernavskii ${ }^{3}$, G.N. Bondarenko ${ }^{1}$ \\ and G.V. Pankina ${ }^{3}$
}

\begin{abstract}
${ }^{1}$ A.V. Topchiev Institute of Petrochemical Synthesis, Russian Academy of Sciences, 29 Leninsky prospect, Moscow 119991, Russia

${ }^{2}$ National University of Science and Technology MISIS, 4 Leninsky prospect, Moscow 119049, Russia

${ }^{3}$ Department of Chemistry, Lomonosov Moscow State University, 1-3 Leninskie Gory, Moscow 119991, Russia
\end{abstract}

\begin{abstract}
Hybrid metal-polymer nanocomposite materials based on polyphenoxazine (PPhOA) and $\mathrm{Fe}_{3} \mathrm{O}_{4}$ nanoparticles were obtained for the first time via two methods: in situ oxidative polymerization of phenoxazine (PhOA) in an aqueous solution of isopropyl alcohol with nanoparticles of $\mathrm{Fe}_{3} \mathrm{O}_{4}$ being present; chemical transformations of PPhOA subjected to IR heating at $400-450{ }^{\circ} \mathrm{C}$ in the presence of $\mathrm{FeCl}_{3} \cdot 6 \mathrm{H}_{2} \mathrm{O}$ in an inert atmosphere. Obtained hybrid $\mathrm{Fe}_{3} \mathrm{O}_{4} / \mathrm{PPhOA}$ nanomaterials were characterized by means of Fourier transform infrared (FTIR) spectroscopy, X-ray diffraction (XRD), transmission electron microscopy (TEM), atomic absorption spectrometry (AAS), elemental analysis, differential scanning calorimetry (DSC), thermogravimetric analysis (TGA), as well as by vibrating sample magnetometry. The chemical structure, phase composition, magnetic and thermal properties of obtained nanocomposites were investigated in relation to the synthesis conditions.
\end{abstract}

Keywords: Polyphenoxazine, Conjugated polymers, Oxidative polymerization in situ, IR heating, Metal-polymer nanocomposite, Magnetic material, $\mathrm{Fe}_{3} \mathrm{O}_{4}$ nanoparticles.

\section{INTRODUCTION}

Hybrid polymer nanomaterials can be singled out from other prospective materials due to their unique physico-chemical properties [1-4]. Among these, the ones with the organic component presented by a polymer with conjugated system and the inorganic component presented by a magnetic nanoparticle are of particular interest. The interaction of nanoparticles and the polymer matrix ensures the multifunctionality of such nanomaterials. Hybrid nanomaterials based on conjugated polymers can reveal splendid electrical, optical, magnetic and electrochemical properties. They are promising for use in healthcare, systems of information storage, electromagnetic screens, contrasting materials for magnetic resonance imaging, electromechanical microsystems, sensors and biosensors, supercapacitors, displays, and other electrochemical devices.

The most effective method of synthesis for the metal-polymer nanocomposites is in situ oxidative polymerization of monomers (aniline, pyrrole) in reaction media containing magnetic nanoparticles $\left(\mathrm{Fe}_{3} \mathrm{O}_{4}, \gamma-\mathrm{Fe}_{2} \mathrm{O}_{3}, \alpha-\mathrm{Fe}_{2} \mathrm{O}_{3}, \mathrm{Co}_{3} \mathrm{O}_{4}\right)$ in the presence of

*Address correspondence to this author at the A.V. Topchiev Institute of Petrochemical Synthesis, Russian Academy of Sciences, 29 Leninsky prospect, Moscow 119991, Russia; E-mail: ozkan@ips.ac.ru oxidizers $\left(\mathrm{H}_{2} \mathrm{O}_{2},\left(\mathrm{NH}_{4}\right)_{2} \mathrm{~S}_{2} \mathrm{O}_{8}, \mathrm{FeCl}_{3}\right)$ [5-13]. Such hybrid nanomaterials usually reveal superparamagnetic properties due to small dimensions and high dispersity of magnetic nanoparticles. Their saturation magnetization $M_{S}$ is within the range $0.06-80.4 \mathrm{emu} / \mathrm{g}$ $[6,8,14-16]$ depending on the composition of the material; it grows along with the content of nanoparticles.

Earlier we have prepared nanostructured magnetic materials based on polydiphenylamine-2-carboxylic acid and $\mathrm{Fe}_{3} \mathrm{O}_{4}$ nanoparticles by polymerization of diphenylamine-2-carboxylic acid in an alkaline medium of $\mathrm{Fe}_{3} \mathrm{O}_{4}$ nanoparticles synthesis, or alternatively under the interfase conditions [17-19]. Monomer is anchored to the $\mathrm{Fe}_{3} \mathrm{O}_{4}$ surface by means of binding the carboxylate ion with $\mathrm{Fe}$ resulting in the $\mathrm{Fe}-\mathrm{OOC}$ bond. The saturation magnetization $M_{S}$ is $27.5-33.5 \mathrm{emu} / \mathrm{g}$. The hybrid nanomaterial obtained under the conditions of in situ interfase polymerization is a superparamagnetic with the content of superparamagnetic particles being close to $100 \%$ (hysteresis loop squareness coefficient $k_{S}=0.007$ ). Other superparamagnetic nanomaterials $\left(k_{S}<0.1\right)$ based on polydiphenylamine [20-22] or polyphenoxazine [23-25] and Co nanoparticles [20, 21, $23,24]$, Co-Fe nanoparticles [25] or those of $\mathrm{Fe}_{3} \mathrm{O}_{4}$ [22] have been prepared under the conditions of IR heating. Obtained values of $k_{S}$ are typical for uniaxial, single- 
domain particles. For $\mathrm{Co}$ and $\mathrm{Fe}_{3} \mathrm{O}_{4}$ the critical dimension of the single-domain state is 20 and $128 \mathrm{~nm}$ respectively $[26,27]$.

In this paper hybrid magnetic nanocomposites based on polyphenoxazine (PPhOA) and $\mathrm{Fe}_{3} \mathrm{O}_{4}$ nanoparticles were prepared for the first time. The comparison was made regarding the structure and properties of nanocomposites obtained in two ways: via in situ oxidative polymerization of phenoxazine (PhOA) in an aqueous solution of isopropyl alcohol with nanoparticles of $\mathrm{Fe}_{3} \mathrm{O}_{4}$ being present; through chemical transformations of PPhOA subjected to IR heating in the presence of $\mathrm{FeCl}_{3} \cdot 6 \mathrm{H}_{2} \mathrm{O}$. Magnetic and thermal properties of obtained nanomaterials were investigated.

\section{EXPERIMENTAL}

Phenoxazine (PhOA) (Acros Organics, 97\%), isopropyl alcohol (high purity grade), toluene (analytical grade), dimethylformamide (DMF) (Acros Organics, $99 \%$ ), $\mathrm{FeCl}_{3} \cdot 6 \mathrm{H}_{2} \mathrm{O}$ (reagent grade), and $\mathrm{FeSO}_{4} \cdot 7 \mathrm{H}_{2} \mathrm{O}$ (reagent grade) were used without any additional purification. Ammonium peroxydisulfate $\left(\mathrm{NH}_{4}\right)_{2} \mathrm{~S}_{2} \mathrm{O}_{8}$ (analytical grade) was purified by recrystallization. Aqueous solutions of the reactants were prepared with the use of distilled water.

Polyphenoxazine (PPhOA) was prepared via in situ oxidative polymerization of $\mathrm{PhOA}$ in an aqueous solution of isopropyl alcohol $\left(M_{w}=2.4 \times 10^{4}\right)$; also in an interfase process using a procedure developed by the authors and described in [28] $\left(M_{w}=3.7 \times 10^{4}\right)$. PPhOA is a blue powder, completely soluble in $N$ methylpyrrolidone, DMF, DMSO, dioxane, acetone, THF, chloroform.

Molecular weight of PPhOA was measured by gel permeation chromatography (GPC) on a Milton Roy instrument equipped with a Milton Roy RI-detector and a PLgel $5 \mu \mathrm{m}$ MIXED-C column using $\mathrm{N}$ methylpyrrolidone as an eluent at $60{ }^{\circ} \mathrm{C}$. The eluent flow rate was $1 \mathrm{ml} / \mathrm{min}$. The volume of injected sample was $150 \mathrm{ml}$. Polystyrene was used for the calibration. The accuracy of $M_{W}$ determination was $\sim 5 \%$.

Synthesis of $\mathrm{Fe}_{3} \mathrm{O}_{4} / \mathrm{PPhOA}$ nanocomposite via in situ oxidative polymerization was conducted in the following manner. First $\mathrm{Fe}_{3} \mathrm{O}_{4}$ nanoparticles were obtained by hydrolysis of iron (II) and (III) salts mixed at the ratio $1: 2$ in the ammonium hydroxide solution at 60 ${ }^{\circ} \mathrm{C}[18,19,29]$. For this purpose, $0.11-0.86 \mathrm{~g}$ of $\mathrm{FeSO}_{4} \cdot 7 \mathrm{H}_{2} \mathrm{O}$ and $0.29-2.35 \mathrm{~g}$ of $\mathrm{FeCl}_{3} \cdot 6 \mathrm{H}_{2} \mathrm{O}$ were dissolved in $20 \mathrm{ml}$ of distilled water, heated to $60{ }^{\circ} \mathrm{C}$, and then $5 \mathrm{ml}$ of $\mathrm{NH}_{4} \mathrm{OH}$ were introduced to the solution. The obtained suspension was heated in water bath to $80{ }^{\circ} \mathrm{C}$ with mixing for $0.5 \mathrm{~h}$, then cooled to the room temperature while being mixed intensively for $1 \mathrm{~h}$. In order to anchor the monomer on the surface of $\mathrm{Fe}_{3} \mathrm{O}_{4}$ the nanoparticles were filtered, rinsed with distilled water up to the neutral reaction of the filtrate, and (without any preliminary drying) introduced into the PhOA solution of $0.1 \mathrm{~mol} / \mathrm{l}(0.55 \mathrm{~g})$ in isopropyl alcohol $(15 \mathrm{ml})$ at $60{ }^{\circ} \mathrm{C}$ and intense mixing for $1 \mathrm{~h}$. The resulting suspension $\left(\mathrm{Fe}_{3} \mathrm{O}_{4} / \mathrm{PhOA}\right.$ in isopropyl alcohol) was likewise cooled to the room temperature while being mixed intensively for $1 \mathrm{~h}$, then down to $0{ }^{\circ} \mathrm{C}$ with continuous intense mixing. In order to conduct in situ oxidative polymerization of PhOA in neutral media on the surface of $\mathrm{Fe}_{3} \mathrm{O}_{4}$ nanoparticles, an aqueous solution of ammonium peroxydisulfate of $0.125 \mathrm{~mol} / \mathrm{l}$ $(0.86 \mathrm{~g})$ was introduced by drops. The volume ratio of aqueous and organic phases was 1:1 (at total volume $30 \mathrm{ml}$ ). The polymerization reaction was conducted for $3 \mathrm{~h}$ at $0{ }^{\circ} \mathrm{C}$ with continuous intense mixing. Upon ending, the product was filtered, rinsed several times with distilled water in order to make it reactant-free, and dried under vacuum over $\mathrm{KOH}$ until the stabilization of weight. The yield of $\mathrm{Fe}_{3} \mathrm{O}_{4} / \mathrm{PPhOA}$ nanocomposite was 0.54 and $1.18 \mathrm{~g}$ for [Fe] contents of 15.1 and $59.6 \%$ respectively (according to atomic absorption spectrometry (AAS) data, Tables 1, 2). When $\mathrm{Fe}_{3} \mathrm{O}_{4} / \mathrm{PPhOA}$ nanocomposite was dispersed in ethyl alcohol, its sedimentation began from the first minutes. The resulting black precipitate revealed magnetic properties when a magnet was put close to it.

In order to synthesize $\mathrm{Fe}_{3} \mathrm{O}_{4} / \mathrm{PPhOA}$ nanocomposite by IR heating, the joint solution was prepared which contained PPhOA obtained in an interfase process and iron (III) chloride $\mathrm{FeCl}_{3} \cdot 6 \mathrm{H}_{2} \mathrm{O}$ dissolved in DMF. Concentration of PPhOA in the DMF solution was $2 \mathrm{wt} \%$, the content of [Fe] was $5-30 \mathrm{wt} \%$ of the polymer weight (not taking the acidic residue into consideration). The precursor (PPhOA and iron (III) chloride) was prepared by evaporation of the solvent (DMF) at $60-85^{\circ} \mathrm{C}$. It was heated by IR radiation in $\mathrm{Ar}$ atmosphere at $400-450{ }^{\circ} \mathrm{C}$ for $2-10 \mathrm{~min}$ using an automatic device of IR heating described in [30]. Heating rate was $50{ }^{\circ} \mathrm{C} / \mathrm{min}$. The yield of $\mathrm{Fe}_{3} \mathrm{O}_{4} / \mathrm{PPhOA}$ nanocomposite was (depending on the synthesis conditions) $76-89 \%$ at [Fe] content $10-26 \%$ (according to AAS data, Tables 1, 2). The obtained metal-polymer $\mathrm{Fe}_{3} \mathrm{O}_{4} / \mathrm{PPhOA}$ nanocomposite had the appearance of a black powder which did not dissolve in organic solvents such as $\mathrm{N}$-methylpyrrolidone, DMF, DMSO. 
Table 1: Atomic-Absorption Spectrometry Data of $\mathrm{Fe}_{3} \mathrm{O}_{4} / \mathrm{PPhOA}$ Nanocomposites and Elemental Analysis Data of PPhOA

\begin{tabular}{|c|c|c|c|c|c|c|}
\hline $\begin{array}{l}\text { Synthesis } \\
\text { method }\end{array}$ & $T,{ }^{\circ} \mathrm{C}$ & $\mathrm{Fe}, \%$ & C, $\%$ & $\mathrm{~N}, \%$ & $H, \%$ & $0, \%$ \\
\hline $\begin{array}{c}\text { In situ } \\
\text { oxidative polymerization }\end{array}$ & 0 & $\begin{array}{c}- \\
15.1 \\
59.6\end{array}$ & $\begin{array}{l}78.7^{*} \\
61.7 \\
25.2\end{array}$ & $\begin{array}{l}7.7 \\
5.6 \\
2.1\end{array}$ & $\begin{array}{l}4.9 \\
3.4 \\
1.6\end{array}$ & $\begin{array}{c}8.7 \\
14.2 \\
11.5\end{array}$ \\
\hline IR heating & 400 & $\begin{array}{l}9.9^{* \star} \\
17.2^{* \star *}\end{array}$ & $\begin{array}{l}61.7 \\
54.6\end{array}$ & $\begin{array}{l}7.1 \\
6.0\end{array}$ & $\begin{array}{l}2.7 \\
1.9\end{array}$ & $\begin{array}{l}18.6 \\
20.3\end{array}$ \\
\hline
\end{tabular}

"Initial PPOA, "[Fe] = $10 \mathrm{wt} \%$ (at the loading),

Table 2: Magnetic Characteristics of $\mathrm{Fe}_{3} \mathrm{O}_{4} / \mathrm{PPOA}$ Nanocomposites

\begin{tabular}{|c|c|c|c|c|c|c|}
\hline $\begin{array}{c}\text { Synthesis } \\
\text { method }\end{array}$ & $\boldsymbol{T},{ }^{\circ} \mathbf{C}$ & [Fe], \% & $\boldsymbol{H}_{\boldsymbol{C}}, \mathbf{O e}$ & $\boldsymbol{M}_{\boldsymbol{S}}$, emu/g & $\boldsymbol{M}_{\boldsymbol{R}}$, emu/g & $\boldsymbol{M}_{\boldsymbol{R}} / \boldsymbol{M}_{\boldsymbol{S}}$ \\
\hline \hline In situ & 0 & 15.1 & 0 & 11.43 & 0 & 0 \\
oxidative polymerization & & 59.6 & 5 & 49.21 & 0.75 \\
\hline IR heating & 400 & $17.2^{*}$ & 269 & 19.35 & 5.3 & 0.015 \\
& & $25.9^{* *}$ & 223 & 25.52 & 7.6 & 0.298 \\
\hline
\end{tabular}

$"[\mathrm{Fe}]=20 \mathrm{wt} \%$ (at the loading), " $[\mathrm{Fe}]=30 \mathrm{wt} \%$.

$H_{C}$ - coercive force, $M_{S}$ - saturation magnetization, $M_{R}-$ residual magnetization, $k_{S}-$ the hysteresis loop squareness coefficient.

The content of metal in $\mathrm{Fe}_{3} \mathrm{O}_{4} / \mathrm{PPhOA}$ nanocomposite was determined quantitatively by AAS using Carl Zeiss Jena AAS 30 spectrophotometer (Tables 1, 2). Fe content was measured with accuracy $\pm 1 \%$.

Fourier transform infrared (FTIR) spectra of PPhOA and $\mathrm{Fe}_{3} \mathrm{O}_{4} / \mathrm{PPhOA}$ nanocomposite were recorded in the range $400-4000 \mathrm{~cm}^{-1}$ using IFS 66v Bruker FTIR spectrometer and processed with the Soft-Spectra software. The samples were dispersed in $\mathrm{KBr}$ and compressed into pellets.

X-ray diffraction (XRD) studies were performed at room temperature using Difray X-ray diffractometer with Bragg-Brentano focus on $\mathrm{Cr}_{\alpha}$-radiation. The diffraction patterns were used to calculate the size distribution of the coherent scattering regions of the crystallites [31] in $\mathrm{Fe}_{3} \mathrm{O}_{4}$ nanoparticles.

Transmission electron microscopy (TEM) microphotographs were taken on a Leo912 AB Omega transmission electron microscope. Size of nanoparticles was determined using the EsiVision software.

A vibration magnetometer was used to study the magnetic characteristics of the samples. The cell of the vibration magnetometer was designed as a flow quartz microreactor, which allowed studying the chemical transformations in the in situ mode [27]. Magnetization of a sample was recorded as function of the value of the magnetic field at room temperature.

Thermogravimetric analysis (TGA) of PPhOA and $\mathrm{Fe}_{3} \mathrm{O}_{4} / \mathrm{PPhOA}$ nanocomposite was performed on TGA/DSC1 unit by Mettler Toledo in a dynamic mode in the range $30-1000{ }^{\circ} \mathrm{C}$ under air and inert nitrogen conditions. The loading of the polymer was $100 \mathrm{mg}$, heating rate $-10{ }^{\circ} \mathrm{C} / \mathrm{min}$, nitrogen flow $-10 \mathrm{ml} / \mathrm{min}$. Calcined aluminum oxide was used as a reference. Sample analysis was carried out in an $\mathrm{Al}_{2} \mathrm{O}_{3}$ crucible.

Differential scanning calorimetry (DSC) was carried out on DSC823e calorimeter by Mettler Toledo. Heating rate was $10{ }^{\circ} \mathrm{C} / \mathrm{min}$ in $\mathrm{Ar}$ flow $(70 \mathrm{ml} / \mathrm{min})$. The results were processed with a service program STARe given with the device.

\section{RESULTS AND DISCUSSION}

Synthesis of hybrid metal-polymer nanocomposite materials based on PPhOA and $\mathrm{Fe}_{3} \mathrm{O}_{4}$ nanoparticles was performed by two methods: in situ oxidative polymerization of $\mathrm{PhOA}$ in an aqueous solution of isopropyl alcohol with nanoparticles of $\mathrm{Fe}_{3} \mathrm{O}_{4}$ being present; IR heating of PPhOA in the presence of iron (III) chloride $\mathrm{FeCl}_{3} \cdot 6 \mathrm{H}_{2} \mathrm{O}$. PPhOA synthesized by the authors for the first time is a semi-ladder heterocyclic polymer which contains nitrogen and also oxygen 
atoms participating in the common system of polyconjugation [28]. Analyses made by FTIR, nuclear magnetic resonance, electron and $\mathrm{X}$-ray photoelectron spectroscopy allowed to visualize the chemical structure of PPhOA as follows:

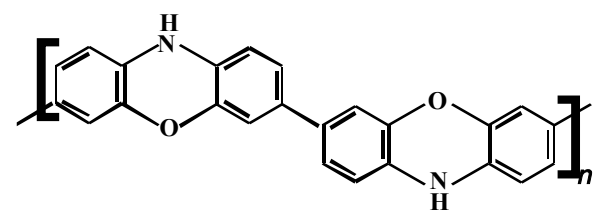

Formation of hybrid metal-polymer nanocomposite materials based on PPhOA and $\mathrm{Fe}_{3} \mathrm{O}_{4}$ nanoparticles in the course of in situ oxidative polymerization of $\mathrm{PhOA}$ in an aqueous solution of isopropyl alcohol in the presence of $\mathrm{Fe}_{3} \mathrm{O}_{4}$ nanoparticles includes: synthesis of $\mathrm{Fe}_{3} \mathrm{O}_{4}$ nanoparticles by hydrolysis of iron (II) and (III) salts mixed at the ratio $1: 2$ in a solution of ammonium hydroxide; anchoring of the monomer (PhOA) on the surface of these nanoparticles in the reaction media of the nanocomposite synthesis; in situ polymerization in neutral media in the presence of oxidizer (an aqueous solution of ammonium peroxydisulfate).
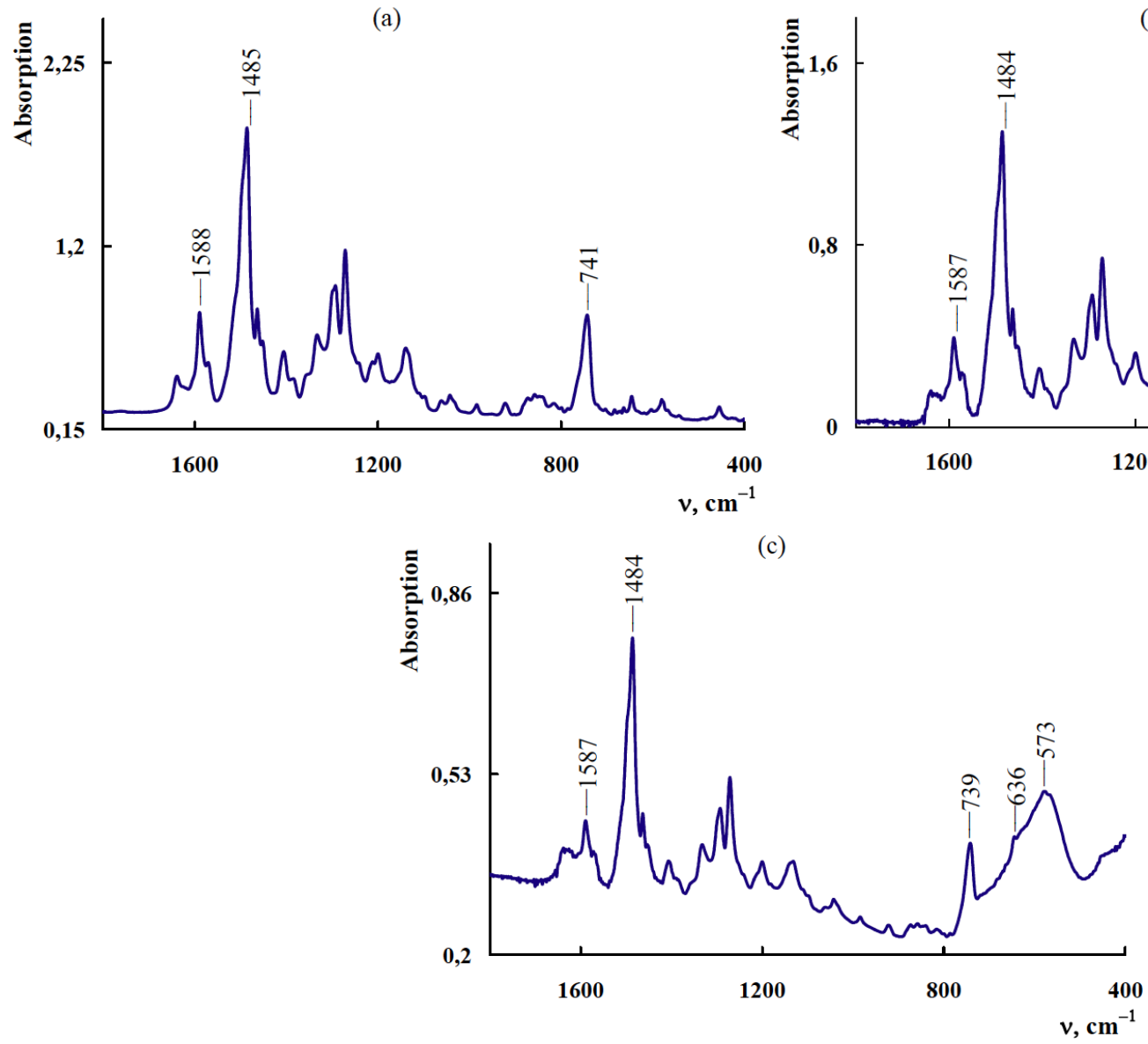

Figure 1: FTIR spectra of PPhOA (a) and $\mathrm{Fe}_{3} \mathrm{O}_{4} / \mathrm{PPhOA}$ nanocomposite prepared by in situ oxidative polymerization at [Fe] = 15.1 (b) and $59.6 \%(\mathbf{c})$.

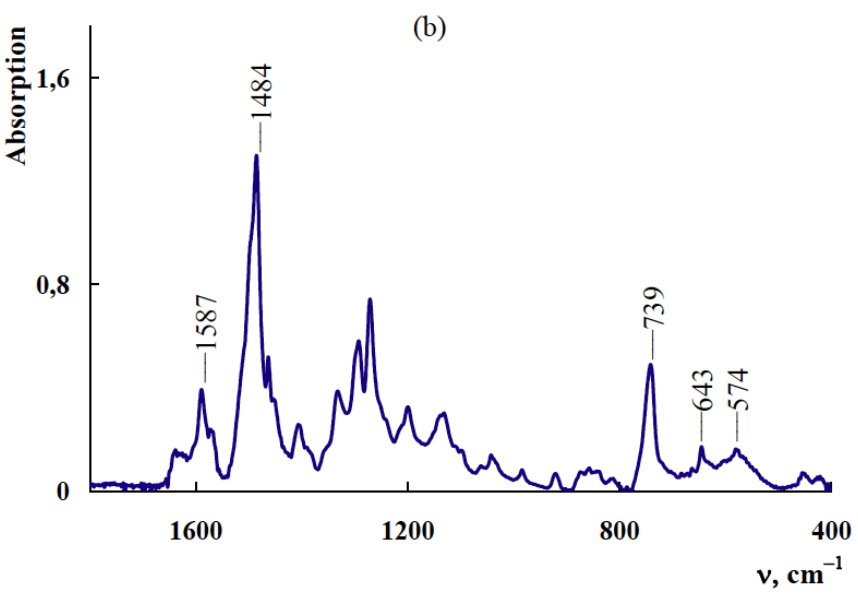

Synthesis of hybrid metal-polymer nanocomposite materials based on PPhOA and $\mathrm{Fe}_{3} \mathrm{O}_{4}$ nanoparticles by IR heating was achieved through chemical transformations of PPhOA subjected to IR radiation in the presence of iron (III) chloride $\mathrm{FeCl}_{3} \cdot 6 \mathrm{H}_{2} \mathrm{O}$ in an inert atmosphere. For these purposes PPhOA obtained under the interfase conditions was used. The use of IR radiation allowed to increase the rates of chemical reactions notably, thus, to decrease the process duration.

Formation of $\mathrm{Fe}_{3} \mathrm{O}_{4} / \mathrm{PPhOA}$ nanocomposite materials was confirmed by TEM, FTIR, XRD, AAS.

Figures 1 and 2 depict the FTIR spectra of $\mathrm{Fe}_{3} \mathrm{O}_{4} / \mathrm{PPhOA}$ nanocomposites obtained via in situ oxidative polymerization and IR heating, respectively. Table 3 presents the attribution of the main characteristic bands in the spectra of PPhOA and nanocomposites. A comparison of IR spectra of polymer and nanocomposite obtained by in situ oxidative polymerization shows that the spectra of nanocomposite have all the main bands which

(c) 

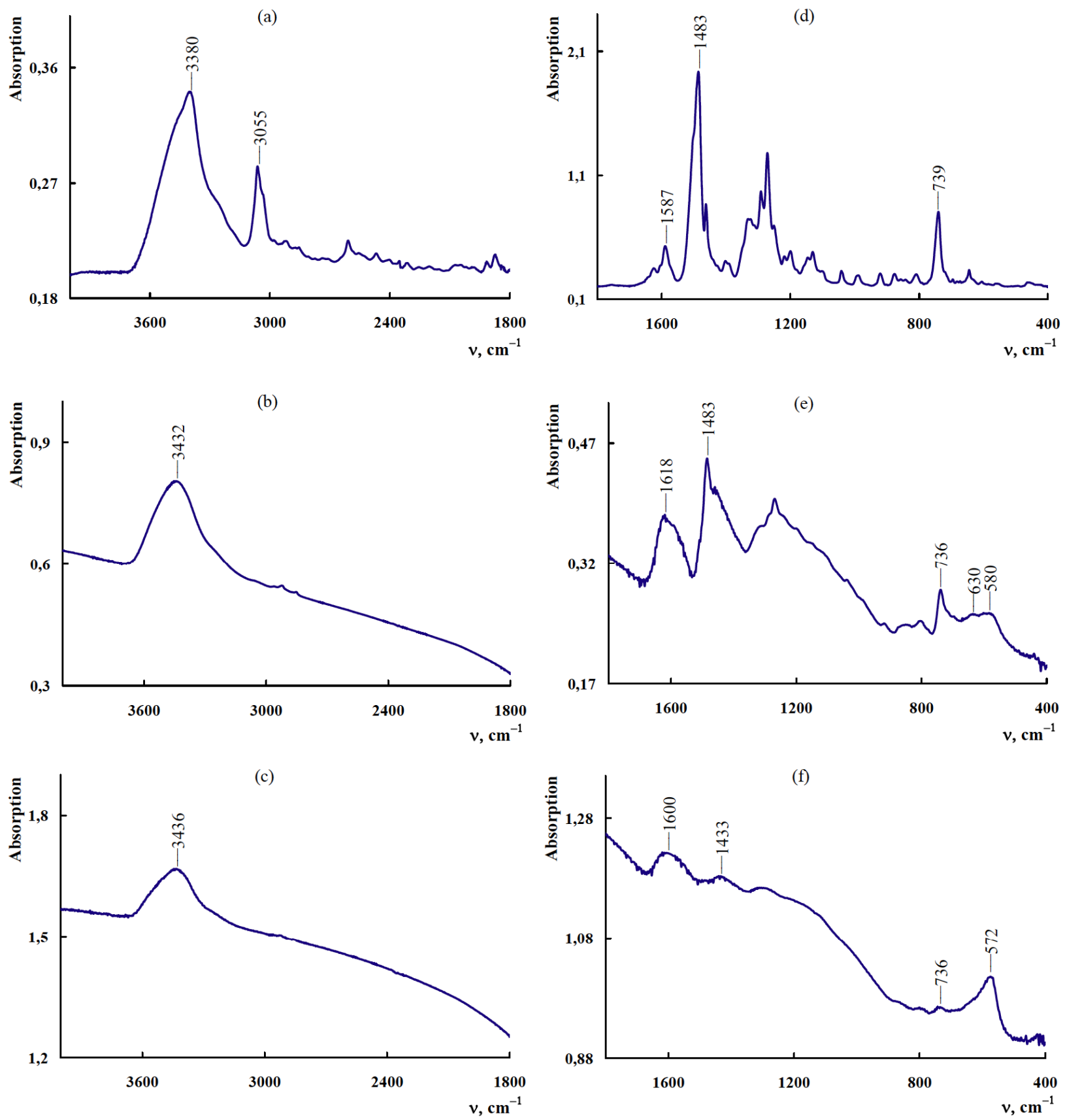

Figure 2: $\mathrm{FTIR}$ spectra of PPhOA (a, d) and $\mathrm{Fe}_{3} \mathrm{O}_{4} / \mathrm{PPhOA}$ nanocomposite prepared by IR heating at $400{ }^{\circ} \mathrm{C}$ for 2 min at $\mathrm{Fe}$ content (at the loading) $10(\mathbf{b}, \mathbf{e})$ and $20 \mathrm{wt} \%(\mathbf{c}, \mathbf{f})$.

characterize the chemical structure of the initial polymer (Figure 1, Table 3 ). As in the case of PPhOA, the growth of the polymer chain in the nanocomposite occurs by $\mathrm{C}-\mathrm{C}$ - joining to phenyl rings in the paraposition regarding to nitrogen. The PPhOA structure contains only benzoid amine groups [28]. A characteristic change for the IR spectra of $\mathrm{Fe}_{3} \mathrm{O}_{4} / \mathrm{PPhOA}$ nanocomposite compared to that of the initial polymer (synthesized in an aqueous solution of isopropyl alcohol) is the presence of the absorption band at $573 \mathrm{~cm}^{-1}$, corresponding to the stretching vibrations of $v_{\mathrm{Fe}-\mathrm{O}}$ bonds (Figure 1). Naturally, an increase in the content of $\mathrm{Fe}_{3} \mathrm{O}_{4}$ in the nanocomposite leads to a significant increase in the intensity of the band at $573 \mathrm{~cm}^{-1}$, characterizing $v_{\mathrm{Fe}-\mathrm{O}}$ bonds.

XRD study of the structure of $\mathrm{Fe}_{3} \mathrm{O}_{4} / \mathrm{PPhOA}$ nanocomposite material obtained via in situ oxidative polymerization allowed to determine that the only phase in this material with presence of metal is $\mathrm{Fe}_{3} \mathrm{O}_{4}$, identified clearly by broad peaks of diffraction in the range of scattering angles $2 \theta=45.8^{\circ}, 54.0^{\circ}, 66.7^{\circ}$, 
Table 3: Attribution of the Main Characteristic Absorption Bands in FTIR Spectra of the Studied Materials

\begin{tabular}{|c|c|c|c|c|}
\hline \multirow[t]{4}{*}{ Attribution of absorption bands } & \multicolumn{4}{|c|}{ Frequency $\mathbf{v}, \mathrm{cm}^{-1}$} \\
\hline & \multicolumn{2}{|c|}{ PPhOA } & \multicolumn{2}{|c|}{$\mathrm{Fe}_{3} \mathrm{O}_{4} / \mathrm{PPhOA}$} \\
\hline & \multicolumn{3}{|c|}{ In situ oxidative polymerization } & \multirow[t]{2}{*}{ IR heating } \\
\hline & $\begin{array}{c}\text { in a solution } \\
\text { of isopropyl alcohol }\end{array}$ & $\begin{array}{l}\text { in an interfase } \\
\text { process }\end{array}$ & $\begin{array}{c}\text { in a solution } \\
\text { of isopropyl alcohol }\end{array}$ & \\
\hline Stretching vibrations $v_{\mathrm{N}-\mathrm{H}}$ & 3380 & 3380 & - & - \\
\hline $\begin{array}{l}\text { Stretching vibrations } v_{\mathrm{C}-\mathrm{H}} \\
\text { in an aromatic ring }\end{array}$ & 3055 & 3055 & 3055 & - \\
\hline $\begin{array}{l}\text { Stretching vibrations } \mathrm{v}_{\mathrm{O}-\mathrm{H}} \\
\text { in } \mathrm{H}_{2} \mathrm{O}\end{array}$ & - & - & 3418 & 3436 \\
\hline $\begin{array}{l}\text { Stretching vibrations } v_{\mathrm{C}-\mathrm{C}} \\
\text { in an aromatic ring }\end{array}$ & 1588,1485 & 1587,1483 & 1587,1484 & 1600,1433 \\
\hline Stretching vibrations $v_{\mathrm{C}-\mathrm{N}}$ & $1330,1291,1270$ & $1326,1290,1270$ & $1330,1291,1270$ & 1291 \\
\hline $\begin{array}{c}\text { Bending vibrations } \\
\delta_{\mathrm{C}-\mathrm{H}} \text { in an 1,2-substituted aromatic ring }\end{array}$ & 741 & 739 & 739 & 736 \\
\hline $\begin{array}{c}\text { Bending vibrations } \\
\delta_{\mathrm{C}-\mathrm{H}} \text { in an } 1,2,4-\text { substituted aromatic ring }\end{array}$ & 869,837 & 869,836 & 869,836 & 869 \\
\hline Stretching vibrations $v_{\mathrm{Fe}-\mathrm{O}}$ & - & - & 573 & 572 \\
\hline
\end{tabular}
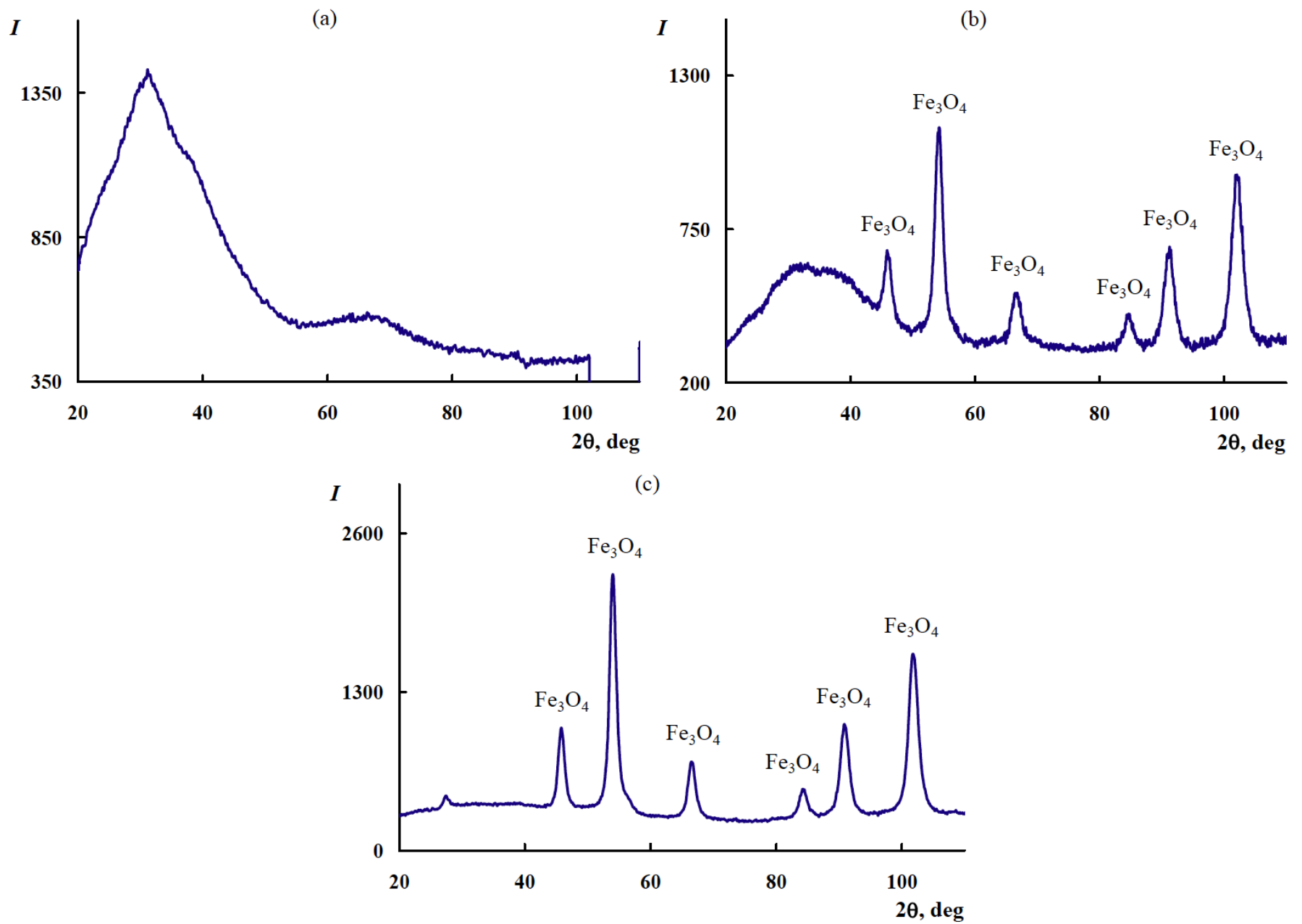

Figure 3: XRD diffractograms of PPhOA (a) and $\mathrm{Fe}_{3} \mathrm{O}_{4} / \mathrm{PPhOA}$ nanocomposite prepared by in situ oxidative polymerization at $[\mathrm{Fe}]=15.1(\mathbf{b})$ and $59.6 \%(\mathbf{c})$. 
<smiles>CCc1ccc2c(c1)Oc1cc(-c3ccc4c(c3)Oc3ccccc3N4)ccc1N2</smiles>

$$
\underset{-2 \mathrm{H}}{\stackrel{\mathrm{FeCl}_{3} \cdot 6 \mathrm{H}_{2} \mathrm{O}, T,{ }^{\circ} \mathrm{C}}{\longrightarrow}}
$$

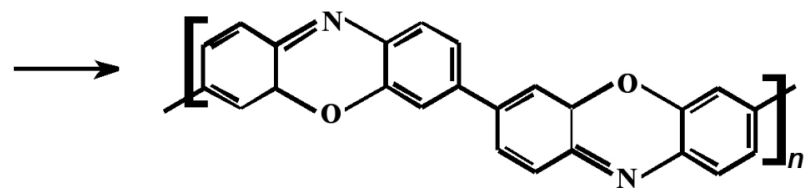

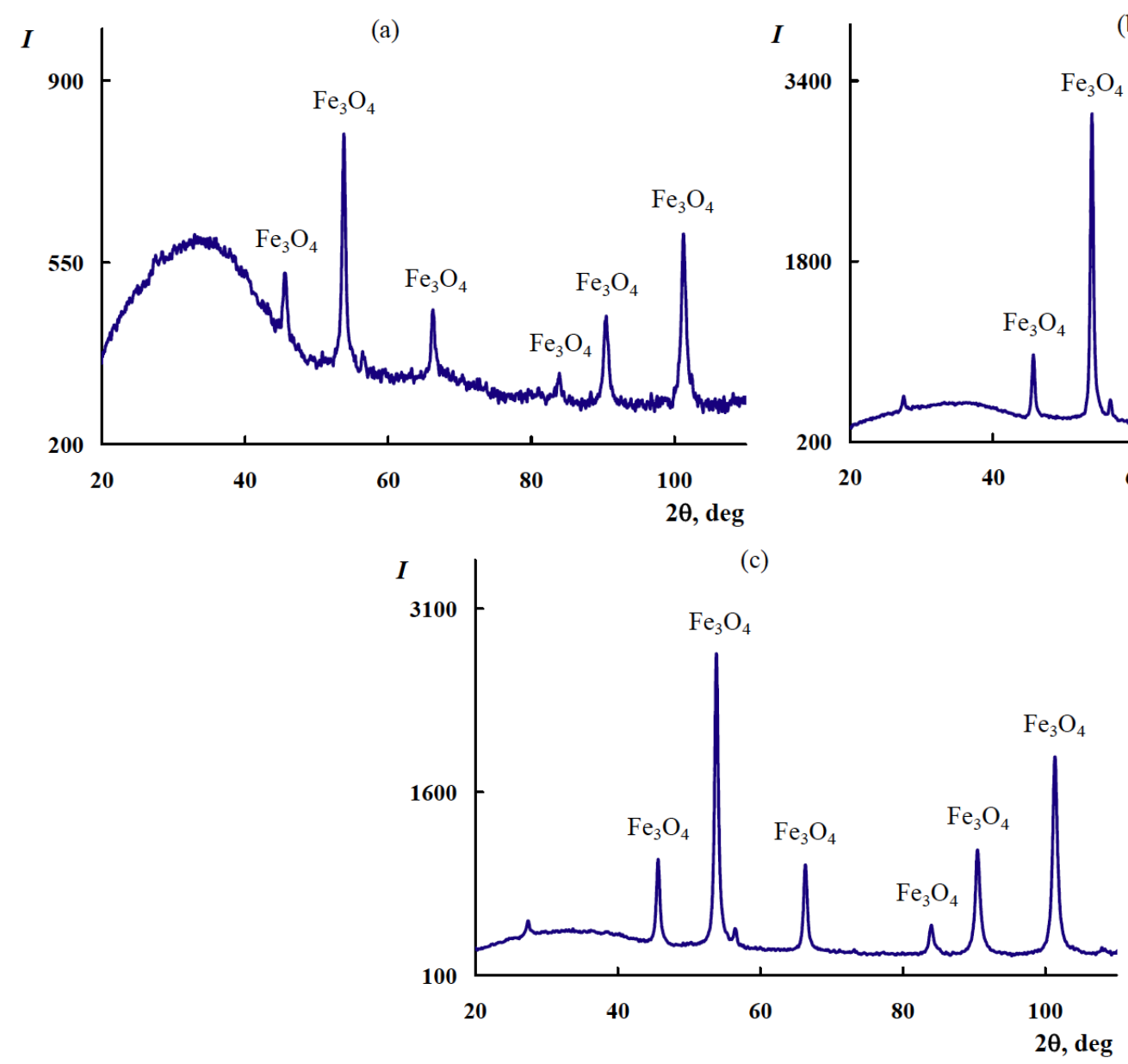

Figure 4: XRD diffractograms of $\mathrm{Fe}_{3} \mathrm{O}_{4} / \mathrm{PPhOA}$ nanocomposite prepared by IR heating at $400{ }^{\circ} \mathrm{C}$ for 2 min at $\mathrm{Fe}$ content (at the loading) 10 (a), 20 (b) and $30 \mathrm{wt} \%$ (c).

$84.5^{\circ}, 90.9^{\circ}$ and $101.9^{\circ}\left(\mathrm{CrK}_{\alpha}\right.$-radiation) (Figure 3$)$. These diffraction peaks correspond to the cubic structure of magnetite (JCPDS 19-0629) and refer respectively to indexes (220), (311), (400), (422), (511) and (440).

It was shown by FTIR spectroscopy that in the course of PPhOA heating by IR radiation at $400-450$ ${ }^{\circ} \mathrm{C}$ in an inert atmosphere in the presence of
$\mathrm{FeCl}_{3} \cdot 6 \mathrm{H}_{2} \mathrm{O}$ the following reactions occur simultaneously: dehydrogenation of phenoxazine structures resulting in formation of $\mathrm{C}=\mathrm{N}$ bonds, and metal reduction by released hydrogen resulting in formation of $\mathrm{Fe}_{3} \mathrm{O}_{4}$ nanoparticles.

According to FTIR data the proceeding of the former reaction (dehydrogenation of phenoxazine structures resulting in formation of $\mathrm{C}=\mathrm{N}$ bonds) can be validated 
by the shift and broadening of the absorption bands at 1587 and $1483 \mathrm{~cm}^{-1}$ which relate to the stretching vibrations of $v_{\mathrm{C}-\mathrm{C}}$ bonds in aromatic rings (Figure 2, Table 3). Absorption bands at 3380 and $3055 \mathrm{~cm}^{-1}$, corresponding to the stretching vibrations of $v_{\mathrm{N}-\mathrm{H}}$ and $v_{\mathrm{C}-\mathrm{H}}$ bonds in phenoxazine structures, are practically absent. New bands appear at 3436 and $572 \mathrm{~cm}^{-1}$, related to the presence of water and to the stretching vibrations of $v_{\mathrm{Fe}-\mathrm{O}}$ bonds, respectively.

Elemental analysis data confirm decrease in hydrogen content in PPhOA in the presence of $\mathrm{FeCl}_{3} \cdot 6 \mathrm{H}_{2} \mathrm{O}$ with temperature of $\mathrm{IR}$ heating growth (Table 1). XRD data confirm that this hydrogen is active in $\mathrm{Fe}$ (III) reduction resulting in formation of magnetite in the form of nanoparticles. Diffractograms of $\mathrm{Fe}_{3} \mathrm{O}_{4} / \mathrm{PPhOA}$ nanocomposite obtained by IR heating show well-defined narrow diffraction peaks of $\mathrm{Fe}_{3} \mathrm{O}_{4}$ in the range of scattering angles $2 \theta=45.66^{\circ}, 53.8^{\circ}$, $66.16^{\circ}, 83.95^{\circ}, 90.36^{\circ}, 101.1^{\circ}$ (Figure 4).

From XRD data the size distribution of $\mathrm{Fe}_{3} \mathrm{O}_{4}$ crystallites was obtained regarding to the coherent scattering regions. Figure $\mathbf{5}$ depicts such distribution depending on the chosen method of nanocomposite synthesis. For the first method (in situ oxidative polymerization), about $97 \%$ of $\mathrm{Fe}_{3} \mathrm{O}_{4}$ crystallites in $\mathrm{Fe}_{3} \mathrm{O}_{4} / \mathrm{PPhOA}$ nanocomposite are of size not exceeding $10 \mathrm{~nm}$ with the maximum of size distribution at $3 \mathrm{~nm}$. According to TEM data the size of $\mathrm{Fe}_{3} \mathrm{O}_{4}$ nanoparticles is within the range $2<d<14 \mathrm{~nm}$ (Figure 6a). As is seen from Figure 5, the second method (IR heating) produces $\mathrm{Fe}_{3} \mathrm{O}_{4} / \mathrm{PPhOA}$ nanocomposite with a broader size distribution curve; the maximum is at 11 $\mathrm{nm}$, and the size of $\mathrm{Fe}_{3} \mathrm{O}_{4}$ nanoparticles by TEM is within the range $4<d<35 \mathrm{~nm}$.

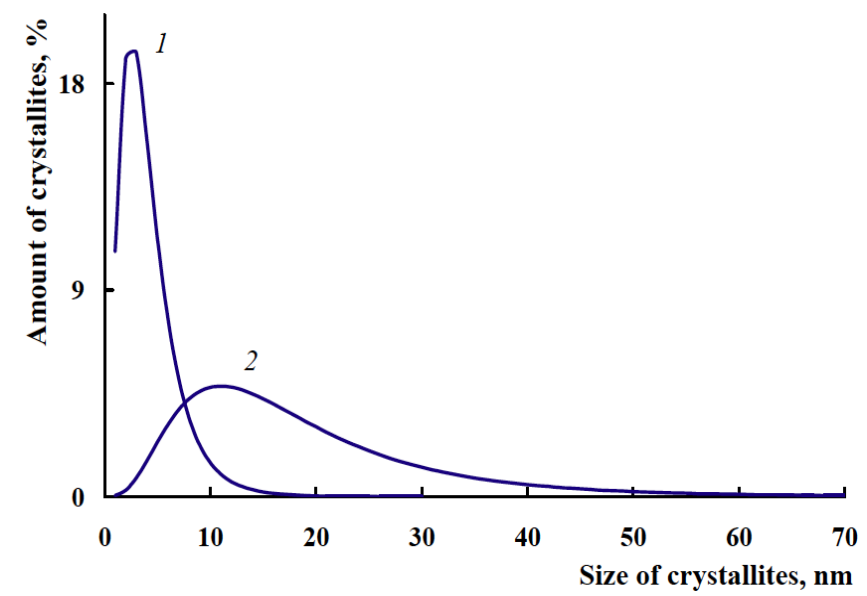

Figure 5: $\mathrm{Fe}_{3} \mathrm{O}_{4}$ crystallites size distribution in $\mathrm{Fe}_{3} \mathrm{O}_{4} / \mathrm{PPhOA}$ nanocomposites prepared by in situ oxidative polymerization (1) and by IR heating (2).

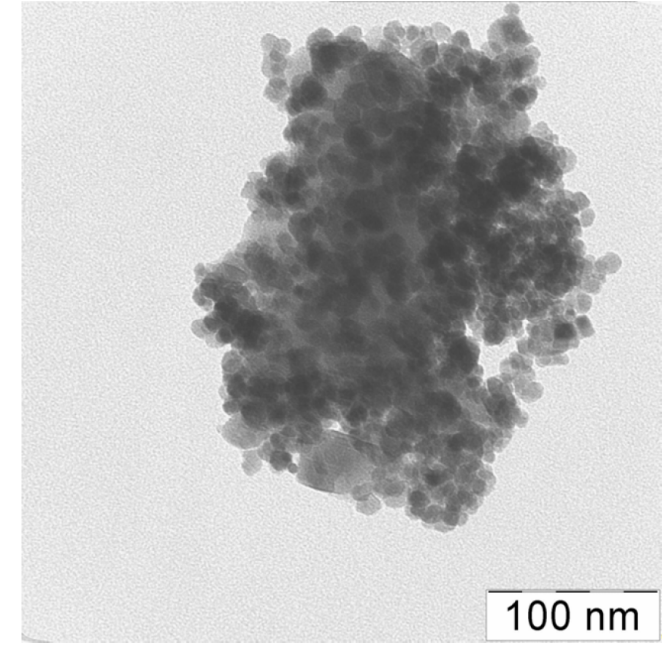

a

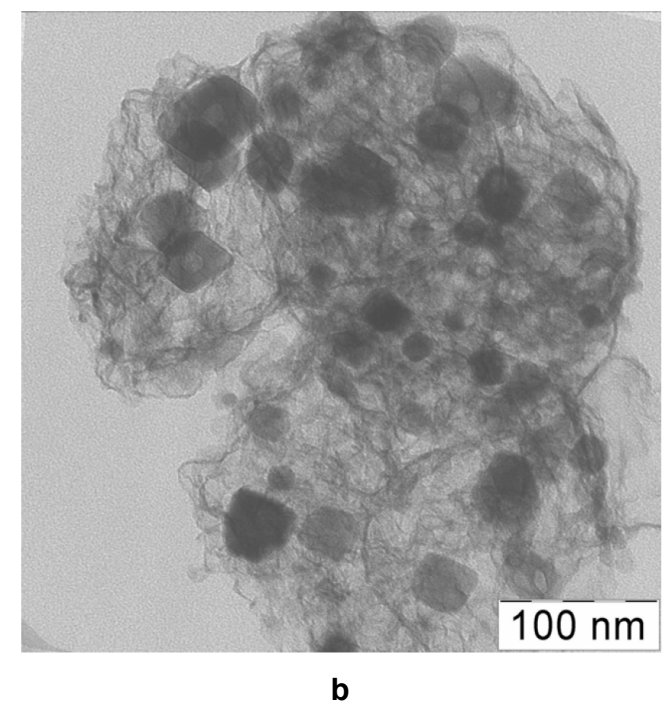

Figure 6: TEM images of $\mathrm{Fe}_{3} \mathrm{O}_{4} / \mathrm{PPhOA}$ nanocomposites prepared by in situ oxidative polymerization (a) and by IR heating at $600{ }^{\circ} \mathrm{C}(\mathbf{b})$.

The influence of synthesis conditions (method of synthesis, temperature, Fe concentration) on the phase composition of $\mathrm{Fe}_{3} \mathrm{O}_{4} / \mathrm{PPhOA}$ nanocomposites was investigated. It is found that the only metal-containing phase in the nanocomposite obtained by in situ oxidative polymerization is magnetite, regardless of $\mathrm{Fe}$ concentration (Figure 3 ). As to the other method (IR heating at $400-450{ }^{\circ} \mathrm{C}$ for $2-10 \mathrm{~min}$ in an inert media), at $\mathrm{Fe}$ concentrations $5-30 \mathrm{wt} \%$ at the loading, only nanoparticles of magnetite are registered (Figure 4). By increasing the iron concentration above $30 \mathrm{wt} \%$ at the loading or decreasing the temperature to $350{ }^{\circ} \mathrm{C}$ in the nanocomposite the degree of reduction is lower and $\mathrm{Fe}_{2} \mathrm{O}_{3}$ nanoparticles can be found as the result of less complete reduction along with those of magnetite. This is confirmed by the XRD reflection peaks of $\mathrm{Fe}_{2} \mathrm{O}_{3}$ in the range of diffraction angles $2 \theta=36.4^{\circ}, 50.3^{\circ}, 62.7^{\circ}$, 
$77.3^{\circ}, 85.2^{\circ}, 104.4^{\circ}$. Temperatures above $450{ }^{\circ} \mathrm{C}$ cause further reduction of $\mathrm{Fe}_{3} \mathrm{O}_{4}$ to $\mathrm{FeO}$ and $\mathrm{Fe}$, confirmed by diffraction peaks at $2 \theta=55.1^{\circ}, 64.5^{\circ}$, $98.04^{\circ}(\mathrm{FeO})$ and $2 \theta=68.87^{\circ}, 106.28^{\circ}(\mathrm{Fe})$. It was established that an increase in temperature leads to a change in morphology of $\mathrm{Fe}_{3} \mathrm{O}_{4}$ nanoparticles. Apart from spherical $\mathrm{Fe}_{3} \mathrm{O}_{4}$ nanoparticles, more coarse square $\mathrm{Fe}_{3} \mathrm{O}_{4}$ nanoparticles of sizes from $45 \times 34 \mathrm{~nm}$ to $57 \times 46 \mathrm{~nm}$ are formed (Figure $6 \mathrm{~b}$ ). It is the result of high propensity of nanoparticles for aggregation [32].

Magnetic properties of $\mathrm{Fe}_{3} \mathrm{O}_{4} / \mathrm{PPhOA}$ nanocomposites depend heavily on the synthesis method. The dependence of the magnetization on the applied magnetic field is given in Figure 7. The values of the main magnetic characteristics of nanocomposites are collected in Table 2. As is seen from Figure 7, for the samples obtained by in situ oxidative polymerization the hysteresis loop squareness coefficient $k_{S}=M_{R} / M_{S} \sim 0$, which testifies to the almost exclusive presence of superparamagnetic nanoparticles. The saturation magnetization $M_{S}$ grows along with the content of $\mathrm{Fe}_{3} \mathrm{O}_{4}$ nanoparticles, achieving $49.21 \mathrm{emu} / \mathrm{g}$ at $[\mathrm{Fe}]=59.6 \%$. The residual magnetization $M_{R}$ is $0-0.75 \mathrm{emu} / \mathrm{g}$. The coercive force $\mathrm{H}_{C}$ is within the range $0-5 \mathrm{Oe}$.

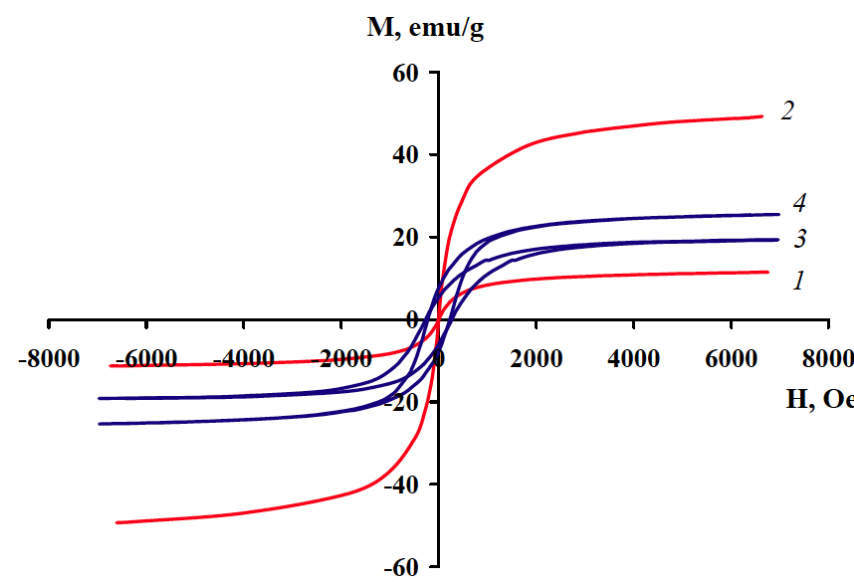

Figure 7: Dependence of magnetization on the applied magnetic field at room temperature for $\mathrm{Fe}_{3} \mathrm{O}_{4} / \mathrm{PPhOA}$ nanocomposites prepared by in situ oxidative polymerization $(1,2)$ and by IR heating $(3,4)$ at $[\mathrm{Fe}]=15.1(1), 59.6(2), 17.2$ (3) and $25.8 \%(4)$.

As is seen from Figure 7 and Table 2, the use of IR heating for the synthesis of $\mathrm{Fe}_{3} \mathrm{O}_{4} / \mathrm{PPhOA}$ nanocomposites produces a large quantity of ferromagnetic particles - the coercive force $H_{C}$ increases up to $269 \mathrm{Oe}$, while the hysteresis loop squareness coefficient $k_{S}=M_{R} / M_{S}$ increases as well up to $0.274-0.298$. The saturation magnetization $M_{S}$ depends on the concentration of $\mathrm{Fe}$; it is within the range $19.35-25.92 \mathrm{emu} / \mathrm{g}$ at $[\mathrm{Fe}]=17.2-25.9 \%$. The residual magnetization $M_{R}$ is $5.3-7.6 \mathrm{emu} / \mathrm{g}$. Thus, the method of IR heating produces ferromagnetic nanocomposite materials.

Thermal stability of obtained $\mathrm{Fe}_{3} \mathrm{O}_{4} / \mathrm{PPhOA}$ nanocomposites was investigated by TGA and DSC. Figures $\mathbf{8}$ and $\mathbf{9}$ depict the temperature dependence of the weight of $\mathrm{Fe}_{3} \mathrm{O}_{4} / \mathrm{PPhOA}$ nanocomposites obtained via two methods (in situ oxidative polymerization; IR heating) in comparison with PPhOA when the samples are heated up to $1000^{\circ} \mathrm{C}$ in the nitrogen flow and in air. Table 4 collects the values of the main thermal properties of the said materials.

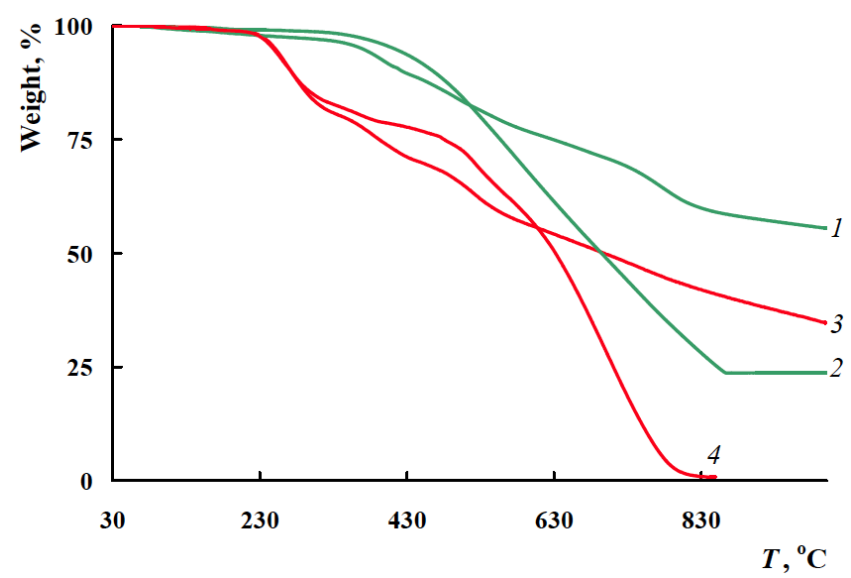

Figure 8: TGA thermograms of $\mathrm{Fe}_{3} \mathrm{O}_{4} / \mathrm{PPhOA}$ nanocomposite $(1,2)$ and PPhOA $(3,4)$ prepared by in situ oxidative polymerization in an aqueous solution of isopropyl alcohol at heating up to $1000{ }^{\circ} \mathrm{C}$ at the rate of $10^{\circ} \mathrm{C} / \mathrm{min}$ in the nitrogen flow $(1,3)$ and in air $(2,4)$.

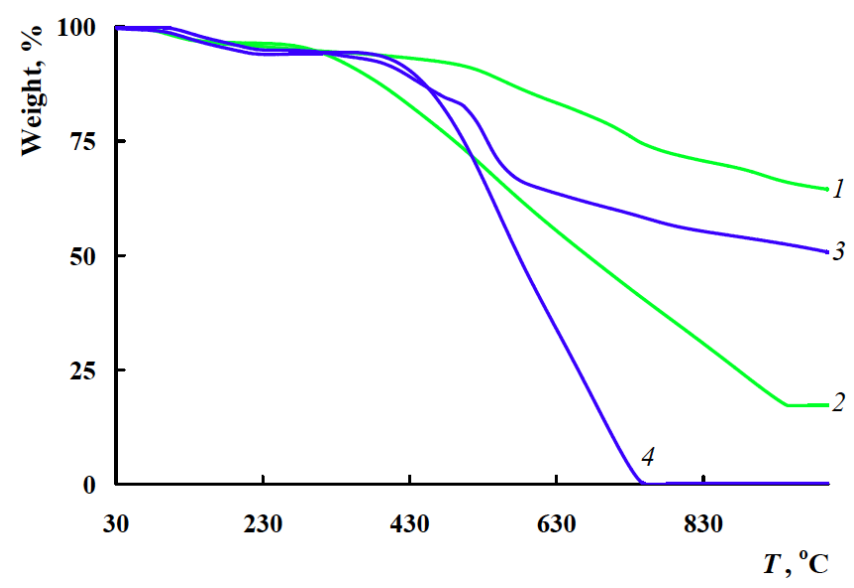

Figure 9: TGA thermograms of $\mathrm{Fe}_{3} \mathrm{O}_{4} / \mathrm{PPhOA}$ nanocomposite prepared by IR heating $(1,2)$ and PPhOA $(3$, 4) at heating up to $1000{ }^{\circ} \mathrm{C}$ at the rate of $10{ }^{\circ} \mathrm{C} / \mathrm{min}$ in the nitrogen flow $(1,3)$ and in air $(2,4)$. PPhOA was obtained by in situ oxidative polymerization in an interfase process.

As is seen from Figure 8, the weight loss is detected at $230{ }^{\circ} \mathrm{C}$ for PPhOA as opposed to $\mathrm{Fe}_{3} \mathrm{O}_{4} / \mathrm{PPhOA}$ 
Table 4: Thermal Properties of the Studied Materials

\begin{tabular}{|c|c|c|c|c|}
\hline \multirow[t]{3}{*}{ Characteristics } & \multicolumn{2}{|c|}{ PPhOA } & \multicolumn{2}{|c|}{$\mathrm{Fe}_{3} \mathrm{O}_{4} / \mathrm{PPhOA}$} \\
\hline & \multicolumn{3}{|c|}{ In situ oxidative polymerization } & \multirow[t]{2}{*}{ IR heating } \\
\hline & $\begin{array}{l}\text { in a solution of } \\
\text { isopropyl alcohol }\end{array}$ & in an interfase process & $\begin{array}{l}\text { in a solution of } \\
\text { isopropyl alcohol }\end{array}$ & \\
\hline${ }^{*} T_{5 \%},{ }^{\circ} \mathrm{C}$ & $248 / 250$ & $189 / 224$ & $411 / 367$ & $297 / 283$ \\
\hline${ }^{* *} T_{50 \%},{ }^{\circ} \mathrm{C}$ & 632 / 697 & $578 />1000$ & $694 />1000$ & $672 />1000$ \\
\hline${ }^{* * *}$ Residue, \% & $0 / 35$ & $0 / 51$ & $24 / 55$ & $17 / 64$ \\
\hline
\end{tabular}

" $T_{5 \%}, " T_{50 \%}$ - temperatures of weight loss 5 and $50 \%$ (Air/Ar), "' residue at $1000{ }^{\circ} \mathrm{C}$ (Air/Ar).

nanocomposite obtained by in situ oxidative polymerization in an aqueous solution of isopropyl alcohol, the conditions of synthesis being the same for both compounds. This weight loss is due to the decomposition of low-molecular fraction present in the polymer, which is supported by DSC data. The DSC thermogram of PPhOA has an endothermic peak at $285^{\circ} \mathrm{C}$ pointing at this decomposition (Figure 10, curve 3). The absence of such peak on the thermogram of polymer at the second heating writes off the possibility of melting at $285^{\circ} \mathrm{C}$. According to XRD data PPhOA is an amorphous polymer (Figure 3a). The fact that the weight is not lost at this temperature in the case of $\mathrm{Fe}_{3} \mathrm{O}_{4} / \mathrm{PPhOA}$ nanomaterial obtained via in situ oxidative polymerization points at the anchoring of polymer on $\mathrm{Fe}_{3} \mathrm{O}_{4}$ nanoparticles.

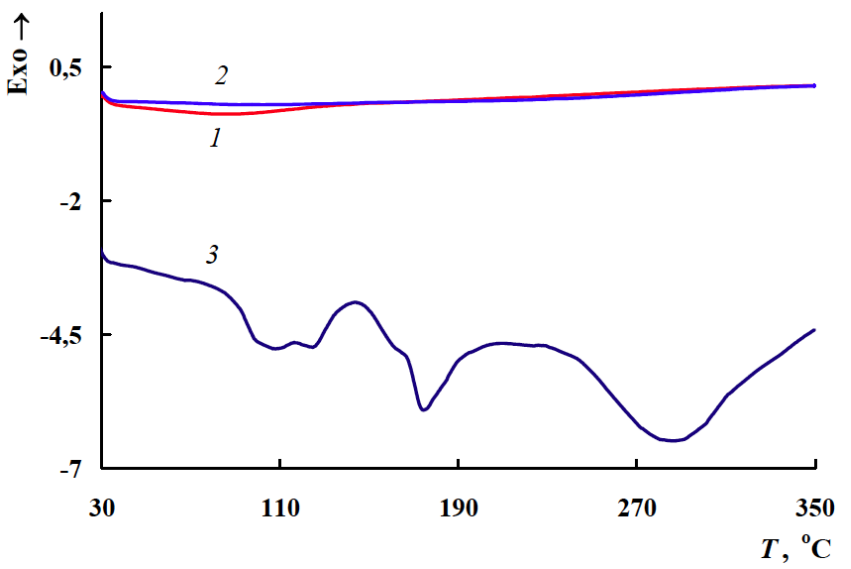

Figure 10: DSC thermograms of $\mathrm{Fe}_{3} \mathrm{O}_{4} / \mathrm{PPhOA}$ nanocomposite prepared by IR heating $(1,2)$ and PPhOA $(3)$ at heating in the nitrogen flow to $350{ }^{\circ} \mathrm{C}$ at the rate of 10 ${ }^{\circ} \mathrm{C} / \mathrm{min}$ (1, 3 - first heating, 2 - second heating).

Figure 9 refers to $\mathrm{Fe}_{3} \mathrm{O}_{4} / \mathrm{PPhOA}$ nanocomposite obtained by IR heating; may we remind that PPhOA in this case has been synthesized in an interfase process. As is seen from Figure 9, after water removal the weight of the nanocomposite remains stable up to 310 ${ }^{\circ} \mathrm{C}$. The absence of weight loss in the nanocomposite in this temperature range is connected to the processes which occur in the course of the nanocomposite synthesis, namely the condensation reaction where the polymer chain grows from the oligomers present in PPhOA [23]. By FTIR data, a conclusion on the growth of the polymer chain can be made from a decrease in intensity of the absorption band at $739 \mathrm{~cm}^{-1}$, which refers to the bending vibrations of $\delta_{\mathrm{C}-\mathrm{H}}$ bonds in the 1,2-substituted benzene ring of the end groups - the lower the intensity, the lower the number of the said groups of polymer (Figure 2).

As is seen from Figures $\mathbf{8}, \mathbf{9}$ and Table 4, $\mathrm{Fe}_{3} \mathrm{O}_{4} / \mathrm{PPhOA}$ nanocomposites prepared by two different methods (in situ oxidative polymerization; IR heating) lose half of their weight in air at 694 and 672 ${ }^{\circ} \mathrm{C}$; at $1000{ }^{\circ} \mathrm{C}$ the initial weight dwindles to 24 and $17 \%$ respectively. In an inert media this process is much slower; at $1000{ }^{\circ} \mathrm{C}$ the respective percentage is 55 and $64 \%$. For PPhOA samples obtained in an aqueous solution of isopropyl alcohol and in an interfase process at $1000{ }^{\circ} \mathrm{C}$ the residue is 35 and $51 \%$ respectively (Table $\mathbf{4}$ ).

\section{CONCLUSIONS}

Hybrid nanocomposite materials based on polyphenoxazine and $\mathrm{Fe}_{3} \mathrm{O}_{4}$ nanoparticles were synthesized for the first time via two methods: in situ oxidative polymerization and IR heating. The structure, magnetic and thermal properties of obtained nanocomposites were investigated. It was established that the size of $\mathrm{Fe}_{3} \mathrm{O}_{4}$ nanoparticles and the magnetic properties of $\mathrm{Fe}_{3} \mathrm{O}_{4} / \mathrm{PPhOA}$ nanomaterials depend on the synthesis method. For the first method (in situ oxidative polymerization) the size of $\mathrm{Fe}_{3} \mathrm{O}_{4}$ nanoparticles is within the range $2<d<14 \mathrm{~nm}$. For the second method (IR heating) the size of $\mathrm{Fe}_{3} \mathrm{O}_{4}$ nanoparticles by TEM is within the range $4<d<35$ $\mathrm{nm}$. For the samples obtained by in situ oxidative polymerization the hysteresis loop squareness 
coefficient $k_{S}=M_{R} / M_{S} \sim 0$, which reveals that almost $100 \%$ of $\mathrm{Fe}_{3} \mathrm{O}_{4}$ nanoparticles are superparamagnetic. The saturation magnetization $M_{S}$ achieves 49.21 emu/g. The use of IR heating for the synthesis of $\mathrm{Fe}_{3} \mathrm{O}_{4} / \mathrm{PPhOA}$ nanocomposites produces a large quantity of ferromagnetic particles. The coercive force $H_{C}$ increases up to 269 Oe, the hysteresis loop squareness coefficient $k_{S}=M_{R} / M_{S}=0.298$, the saturation magnetization $M_{S}$ is $25.92 \mathrm{emu} / \mathrm{g}$. Obtained nanocomposites are of high thermal stability. $\mathrm{Fe}_{3} \mathrm{O}_{4} / \mathrm{PPhOA}$ nanocomposites prepared via two different methods (in situ oxidative polymerization; IR heating) lose half of their weight in air at 694 and 672 ${ }^{\circ} \mathrm{C}$. In an inert media at $1000{ }^{\circ} \mathrm{C}$ the residue is 55 and $64 \%$ respectively.

\section{ACKNOWLEDGMENTS}

The authors express their sincere gratitude to G.A. Shandryuk (A.V. Topchiev Institute of Petrochemical Synthesis, RAS) for conducting the TGA, DSC analyses of $\mathrm{Fe}_{3} \mathrm{O}_{4} /$ polyphenoxazine nanocomposites.

\section{REFERENCES}

[1] Sellinger A, Weiss PM, Nguyen A, et al. Continuous selfassembly of organic-inorganic nanocomposite coatings that mimic nacre. Nature 1998; 394: 256-60. https://doi.org/10.1038/28354

[2] Yamamoto K, Sakata Y, Nohara Y, Takahashi Y, Tatsumi T. Organic-inorganic hybrid zeolites containing organic frameworks. Science 2003; 300: 470-2. https://doi.org/10.1126/science.1081019

[3] Gerasin VA, Antipov EM, Karbushev VV, et al. New approaches to the development of hybrid nanocomposites: from structural materials to high-tech applications. Russ Chem Rev 2013; 82: 303-32. https://doi.org/10.1070/RC2013v082n04ABEH004322

[4] Pomogailo AD, Rozenberg AT, Uflyand IE. Metal nanoparticles in polymers Khimiya, Moscow, 2000; p. 672. [in Russian]

[5] Yang $\mathrm{C}$, Du J, Peng Q, et al. Polyaniline/ $\mathrm{Fe}_{3} \mathrm{O}_{4}$ nanoparticle composite: synthesis and reaction mechanism. J Phys Chem B 2009; 113: 5052-8. https://doi.org/10.1021/jp811125k

[6] Qiu G, Wang Q, Nie M. Polyaniline/ $\mathrm{Fe}_{3} \mathrm{O}_{4}$ magnetic nanocomposite prepared by ultrasonic irradiation. J Appl Polym Sci 2006; 102: 2107-11 https://doi.org/10.1002/app.24100

Khan A, Aldwayan AS, Alhoshan M, Alsalhi M. Synthesis by in situ chemical oxidative polymerization and characterization of polyaniline/iron oxide nanoparticle composite. Polym Int 2010; 59: 1690-4.

https://doi.org/10.1002/pi.2908

[8] Umare SS, Shambharkar BH. Synthesis, characterization, and corrosion inhibition study of polyaniline- $\alpha-\mathrm{Fe}_{2} \mathrm{O}_{3}$ nanocomposite. J Appl Polym Sci 2013; 127: 3349-55. https://doi.org/10.1002/app.37799

[9] Mallikarjuna NN, Manohar SK, Kulkarni PV, Venkataraman A, Aminabhavi TM. Novel high dielectric constant nanocomposites of polyaniline dispersed with $\mathrm{Y}-\mathrm{Fe}_{2} \mathrm{O}_{3}$ nanoparticles. J Appl Polym Sci 2005; 97: 1868-74. https://doi.org/10.1002/app.21405
[10] Bhaumik M, Leswifi TY, Maity A, Shrinivasu VV, Onyango MS. Removal of fluoride from aqueous solution by polypyrrole/ $\mathrm{Fe}_{3} \mathrm{O}_{4}$ magnetic nanocomposite. J Hasardous Mater 2011; 186: 150-9.

https://doi.org/10.1016/j.jhazmat.2010.10.098

[11] Jokar $M$, Foroutani $R$, Safaralizadeh $M H$, Farhadi $K$ Synthesis and characterization of polyaniline $/ \mathrm{Fe}_{3} \mathrm{O}_{4}$ magnetic nanocomposite as practical approach for fluoride removal process. Ann Res Rev Biol 2014; 4: 3262-73. https://doi.org/10.9734/ARRB/2014/9108

[12] Shambharkar $\mathrm{BH}$, Umare SS. Production and characterization of polyaniline/ $\mathrm{Co}_{3} \mathrm{O}_{4}$ nanocomposite as a cathode of Zn-polyaniline battery. Mater Sci Eng B 2010; 175: 120-8. https://doi.org/10.1016/j.mseb.2010.07.014

[13] Chen A, Wang H, Zhao B, Wang J, Li X. Preparation and characterization of $\mathrm{Fe}_{3} \mathrm{O}_{4}$ /polypyrrole(PPy) composites. Acta Mater Compos Sin 2004; 21: 157-60.

[14] Aphesteguy JC, Jacobo SE. Composite of polyaniline containing iron oxides. Physica B 2004; 354: 224-7. https://doi.org/10.1016/j.physb.2004.09.053

[15] Wan M, Li J. Synthesis and electrical-magnetic properties of polyaniline composites. J Polym Sci A Polym Chem 1998; 36: 2799-805.

https://doi.org/10.1002/(SICl)10990518(19981115)36:15<2799::AID-POLA17>3.0.CO;2-1

[16] Zhang Z, Wan M. Nanostructures of polyaniline composites containing nano-magnet. Synth Met 2003; 132: 205-12. https://doi.org/10.1016/S0379-6779(02)00447-2

[17] Karpacheva GP, Ozkan SZh. RU Patent for the invention of "Dispersed nanocomposite magnetic material and method of its obtaining" 2011; № 2426188.

[18] Eremeev IS, Ozkan SZh, Karpacheva GP, Bondarenko GN Hybrid dispersed magnetic nanomaterial based on polydiphenylamine-2-carbonic acid and $\mathrm{Fe}_{3} \mathrm{O}_{4}$ Nanotechnologies in Russia 2014; 9: 38-44. https://doi.org/10.1134/S1995078014010054

[19] Karpacheva GP, Ozkan SZh, Eremeev IS, Bondarenko GN Dzidziguri EL, Chernavskii PA. Synthesis of hybrid magnetic nanomaterial based on polydiphenylamine-2-carboxylic acid and $\mathrm{Fe}_{3} \mathrm{O}_{4}$ in the interfacial process. Eur Chem Bull 2014; 3 : 1001-7.

[20] Karpacheva G, Ozkan S. Polymer-metal hybrid structures based on polydiphenylamine and Co nanoparticles. Procedia Mater Sci 2013; 2: 52-9. https://doi.org/10.1016/j.mspro.2013.02.007

[21] Ozkan SZh, Dzidziguri EL, Chernavskii PA, Karpacheva GP Efimov MN, Bondarenko GN. Metal-polymer nanocomposites based on polydiphenylamine and cobalt nanoparticles. Nanotechnologies in Russia 2013; 8: 452-60. https://doi.org/10.1134/S1995078013040113

[22] Ozkan SZh, Dzidziguri EL, Karpacheva GP, Chernavskii PA Efimov MN, Bondarenko GN. A magnetic metal-polymer nanocomposite material based on polydiphenylamine and $\mathrm{Fe}_{3} \mathrm{O}_{4}$ nanoparticles. Russ Chem Bull 2015; 64: 196-201. https://doi.org/10.1007/s11172-015-0842-5

[23] Karpacheva GP, Ozkan SZh, Dzidziguri EL, et al. Hybrid metal-polymer nanocomposites based on polyphenoxazine and cobalt nanoparticles. Eur Chem Bull 2015; 4: 135-41.

[24] Karpacheva GP, Ozkan SZh. RU patent for the invention of "Polymer dispersed magnetic material and method for production thereof", № 2601005 from 27.10.2016

[25] Ozkan SZh, Karpacheva GP, Dzidziguri EL, et al. One step synthesis of hybrid magnetic material based on polyphenoxazine and bimetallic Co-Fe nanoparticles. Polym Bull 2016. https://doi.org/10.1007/s00289-016-1878-x

[26] Gubin SP, Koksharov YuA, Khomutov GB, Yurkov GYu. Magnetic nanoparticles: preparation, structure and properties. Rus Chem Rev 2005; 74: 489-520. https://doi.org/10.1070/RC2005v074n06ABEH000897 
[27] Chernavskii PA, Pankina GV, Lunin VV. Magnetometric methods of investigation of supported catalysts. Russ Chem Rev 2011; 80: 579-604. https://doi.org/10.1070/RC2011v080n06ABEH004187

[28] Ozkan SZh, Karpacheva GP, Bondarenko GN. Polymers of phenoxazine: synthesis, structure. Russ Chem Bull 2011; 60: 1651-6.

https://doi.org/10.1007/s11172-011-0247-z

[29] Massart R. Preparation of aqueous magnetic liquids in alkaline and acidic media. IEEE Trans Magn 1981; 17: 12478.
https://doi.org/10.1109/TMAG.1981.1061188

[30] Zemtsov LM, Karpacheva GP, Efimov MN, Muratov DG Bagdasarova KA. Carbon nanostructures based on IRpyrolyzed polyacrylonitrile. Polym Sci A 2006; 48: 633-7. https://doi.org/10.1134/S0965545X06060125

[31] Dzidziguri EL. Dimensional characteristics of nanopowders. Nanotechnologies in Russia 2009; 4: 857-70. https://doi.org/10.1134/S1995078009110147

[32] Gubin SP. What is nanoparticle? Development trends for nanochemistry and nanotechnology. Ross Khim Zh 2000; 44: 23-31. 